\title{
Reseñas y notas bibliográficas
}

\author{
Alegría Olazábal, Tito y Gerardo Ordóñez Barba, \\ Legalizando la ciudad. Asentamientos informales y procesos \\ de regularización en Tijuana, Tijuana, El Colegio de la \\ Frontera Norte, 2005
}

\section{Boris Graizbord*}

Los sistemas de propiedad de la tierra incluyen arreglos legales, contractuales y consuetudinarios por los cuales los individuos y organizaciones acceden a oportunidades económicas y sociales por medio de la tierra. La forma de propiedad se basa en reglas y procedimientos que gobiernan los derechos y responsabilidades de los grupos y los individuos en el uso y control del recurso tierra. De hecho, la institucionalidad de la tenencia de la tierra es el medio para determinar la distribución del ingreso. Así, tierra sin tenencia es un concepto vacío. Pero la tenencia de la tierra representa un conjunto complejo de derechos para usar el espacio que incluye el derecho de acceso, el de ocupación y desarrollo, y todos los privilegios que se asocian con un sitio y lo que hay por encima y por debajo del mismo, aunque no en nuestro país, donde el subsuelo es propiedad de la nación. Sin embargo estos derechos y privilegios de propiedad están acotados por importantes restricciones: estatutos, contigüidad o vecindad, proximidad, y otras como el interés superior de la comunidad. Esto es especialmente cierto, pues en un mundo civilizado ningún individuo puede tener derecho absoluto sobre la tierra, de ahí que su regulación refleje el desarrollo institucional de la sociedad.

De hecho, la regulación intenta controlar el derecho del propietario de gozar toda la superficie, de aprovecharla, de desarrollarla y mejorarla, de obtener beneficios, de disponer de ella, pero también de no hacer nada. Por supuesto, el bienestar social debe imponer restricciones o regulaciones, de aquí la importancia de los instrumentos al alcance del Estado para defender los intereses superiores sobre los del individuo en particular.

* Profesor investigador del Centro de Estudios Demográficos, Urbanos y Ambientales de El Colegio de México. Correo electrónico: graiz@colmex.mx.

ESTUDIOS DEMOGRÁFICOS Y URBANOS, VOL. 21, NÚM. 3 (63), PP. 757-761 
Cabe por último señalar que lo que adquiere valor en el mercado no es la tierra, o lo que en ella existe como tal, sino los derechos e intereses del individuo que la posee. En fin, la tierra no es un bien cuyo valor pueda definir condiciones de competencia perfecta. No se tiene conocimiento perfecto, hay elementos monopólicos inherentes a la propiedad, la propiedad es de naturaleza individual y única, lo que se construye sobre ella tiene un tiempo de amortización, el proceso de desarrollo lleva tiempo y es cambiante, la intervención del Estado se da en distintos niveles, y los costos de administración, transferencia o traspaso y escrituración contribuyen a producir condiciones de mercado altamente imperfectas.

El valor, entonces, está dado por estas incertidumbres y riesgos que se producen por la combinación de las anteriores características. Se incluyen aquí el acceso al crédito y el acceso al mercado de vivienda en renta. De ahí que la planeación, es decir, la intervención del Estado que afecta estos atributos, implique una redistribución de valores del suelo y, por tanto, de riqueza de patrimonio en el conjunto de la comunidad. Las acciones públicas, al asignar usos, zonificar, alterar la accesibilidad, proporcionar servicios y equipamiento, mejorar la calidad ambiental o en general proteger o controlar y regular, producen efectos redistributivos. En este sentido se pueden entender los argumentos de Alegría y Ordóñez al relacionar la regulación con la consolidación y con las condiciones de vida o la mejora socioeconómica (p. 53). Me parece que el modelo es regulación $\rightarrow$ consolidación y consolidación $\rightarrow$ regulación, es decir, pudiera ser recursivo (aunque no lo es en este caso, por razones que referiré).

En efecto, como dicen los autores (p. 54), la consolidación de una zona podría mejorar:

1) Las condiciones físicas de habitabilidad;

2) la infraestructura urbana; $y$

3) las relaciones de los habitantes con la ciudad en tres escalas diferentes, vivienda, barrio, estructura urbana.

El libro se divide en cuatro partes: I) un análisis de las características de la población y de las viviendas irregulares; II) las implicaciones de la irregularidad; III) los instrumentos institucionales en manos del Estado para manejar el problema; $I V$ ) conclusiones y recomendaciones de política para mejorar el conjunto de organismos regularizadores, los sistemas de registro catastral y control del crecimiento, y la planea- 
ción del crecimiento urbano. Una introducción explica el tema y se incluyen varios anexos estadísticos y cartográficos.

Está bien escrito y es importante. ¿Por qué? Porque se trata de un ejercicio de evaluación de política que en el contexto de mayor apertura, transparencia y relevo político es cada vez más necesario en nuestro país para reducir el derroche y ser más eficaces en la consecución de metas y objetivos sociales. Pero técnicamente es importante para resolver los defectos del proceso de diseño, implementación y evaluación de políticas. En efecto, los gobiernos generalmente: 1) no saben si las muchas cosas que hacen deben realmente hacerse, y 2) cuando deciden que algo debe hacerse, no saben cómo y con qué instrumentos es posible obtener los resultados deseados.

No se trata sólo de evaluar la actividad y el desempeño sino también el impacto. La primera concierne a saber hasta dónde un programa o política se ha adoptado de acuerdo con los lineamientos establecidos. El segundo permite conocer si un programa, una acción o una forma de actuar se realizan como estaba planeado, pero también medir si de éstos se han obtenido resultados consistentes con las intenciones previstas.

En el fondo de toda evaluación está la idea de causalidad, pero las relaciones de causa y efecto no pueden verse; es necesario construir modelos (proxis) que permitan conocer indirectamente, valiéndose de instrumentos estadísticos, las relaciones entre variables que representan las acciones y los resultados obtenidos.

Un aporte del trabajo de Alegría y Ordóñez que aparece en la primera parte y en las conclusiones (p. 119) es que "en Tijuana -y advierten a los lectores que pudiera no ser generalizable- el modo irregular en el acceso y la tenencia de la tierra ha sido tan importante como el regular". En efecto, la irregularidad -dicen- es la alternativa al alcance de la población de bajos ingresos para satisfacer su necesidad de suelo y vivienda. Sin embargo no pueden concluir que en esos predios toda la población sea pobre. De hecho la diferencia promedio de sus salarios mínimos mensuales es pequeña: de 3.9 a 4.3 en toda la zona censada (cuadro Anexo II.2, p. 146). Tampoco hay diferencias en ocupación: el promedio de 4.6 habitantes por vivienda en los predios es igual al de toda la zona censada (idem).

Y así la mayoría de los indicadores, incluyendo la inmigración, aunque por razones obvias en las zonas de mayor crecimiento actual hay una mayor proporción de inmigrantes recientes (p. 121). Y concluyen: "La irregularidad de la tenencia de la tierra no es sinónimo de 
pobreza" cuestión central para eliminar argumentos populistas que sólo sirven para defender el statu quo y mantener el desapego a la ley.

Esto último impera, pues no sólo la población reproduce esta condición de vida fuera del "estado de derecho". Más aún si como dicen los autores (p. 62), los beneficios de la renta sobrepasan los costos derivados de los riesgos de la irregularidad. Incluso los mismos organismos públicos, como el Fovissste (p. 69), han edificado unidades habitacionales en condiciones de irregularidad. Y por eso no es de interés general regularizar, de aquí que la de la regulación y la consolidación no sea una relación recursiva.

Todas las dependencias han desempeñado un papel que deja mucho que desear, sin embargo el municipio es el actor central que ha de enfrentar este problema. Pero he aquí el mayor cuello de botella, o el surrealismo total: las facultades y obligaciones de los municipios llevan a pensar que son omnipotentes (p. 89). La lista es impresionante, pero el costo de ejercerlas y cumplirlas, salvo quizá para algunos municipios metropolitanos -y quién sabe-, es prohibitivo. Es prohibitivo en tanto que las características de la mayoría son:

i) incapacidad organizativa;

ii) insuficiencia de personal capacitado;

iii) insolvencia financiera;

iv) recursos humanos y técnicos limitados;

v) débil compromiso con la ciudadanía que los elige una sola vez;

vi) deficiente control jurisdiccional.

Asimismo las funciones de los organismos reguladores se ven afectadas por:

i) incapacidad;

ii) prácticas de trabajo viciadas;

iii) corrupción.

Y ambas instancias por:

i) ausencia de instrumentos internos de planeación y externos (marco normativo y legal) y la crónica;

ii) debilidad de los órganos para aplicar la ley. 
Como respuesta a estas limitaciones, los autores proponen una serie de medidas que cubren desde la reestructuración de los organismos regularizadores, el control de la expansión urbana y los sistemas de registro de la propiedad, hasta recomendaciones sobre la planeación del crecimiento urbano y el fomento de suelo y de vivienda en los ámbitos municipal y estatal. Finalmente señalan rutas que favorecen la coordinación de los tres órdenes de gobierno y el establecimiento de políticas de financiamiento de fraccionamientos progresivos y de apoyo crediticio.

En fin, un libro como éste, de fácil lectura, accesible y cuidado, va a ser de gran utilidad, si no para eliminar estas limitaciones o insuficiencias, sí para capacitar, informar y propiciar que los funcionarios que intervienen en estos procesos puedan consultar y encontrar argumentos y propuestas para llevar a cabo sus funciones con mayor conocimiento de causa y en el marco de una lógica de planificación que racionalice su desempeño.

Faltaría, quizá, referirse a lo implícito. En este sentido sé que Tito Alegría, y seguramente Gerardo Ordóñez, conocen y son estudiosos de la economía urbana. Este libro nos brindará satisfacción especial a los interesados en el desarrollo de esta disciplina, pues los argumentos, la interpretación de los resultados y las propuestas reflejan un enfoque analítico y no sólo político o ideológico, como suele ocurrir cuando se tratan estos temas. 